This article has been scanned by iThenticat No plagiarism detected

Volume 3, Issue 3, June 2021

p. $148-159$

COGNITIVE INTEGRATION IN THE CONTEXT OF INTERCULTURAL STUDIES:

EDUCATIONAL EXTENSIONS OF THE RELATIONSHIP BETWEEN THE DIRECTION OF WRITING AND THE SPATIAL REPRESENTATION OF THE CONCEPT OF TIME AS

\title{
A MODEL
}

http://dx.doi.org/10.47832/2757-5403.3-3.14

Hasbiya Taifi BERNOUSSI ${ }^{1}$

\begin{abstract}
:
The concept of time has cultural characteristics, as it is the product of a symbolic communicative context that draws its characteristics from its founding group. Hence, the concept of time is shaped and represented mentally according to its socio-cultural context. Accordingly, it seems legitimate to examine its cultural specificity.

This study tackles the nature of the spatial representation of the concept of time, as this latter is carried through cultural mediums, namely the oral and written language. The target group includes 32 unschooled children aged between 10 and 11 . It is worth mentioning that many intercultural studies have indicated the existence of a definite, statistically significant relationship between the concept of time on the one hand and the direction of writing on the other hand. As the spatial representation of the concept of time in children of French culture is from left to right, influenced by the direction of French writing. Whereas, the spatial representation of the concept of time in children of French-Maghreb culture is in both directions (right $\square$ left) and (right $\square$ left), that is, in the form of congruous formula between the two directions of French writing from left to right and Arabic from right to left.

The study confirms, in its third context, the spatial representation of the concept of time among uneducated children who do not know how to read and write, the results of previous studies on the concept of time in its relationship to the direction of writing. Where the space-time orientation is characterized by the multiplicity and diversity (right $\square$ left, left $\square$ right, top $\square$ bottom, top $\square$ bottom...), regardless of the direction of presentation of the images by the experimenter.

Studies, with their integral depth, confirm that it is a matter of cultural learning; the school institution as a social unit with symbolic and communicative contexts works to impart our concepts, including the concept of time, the characteristics of the socio-cultural context. The

\footnotetext{
${ }^{1}$ Dr. , Mohammed V University in Rabat, Morocco, fes2025@gmail.com, https://orcid.org/0000-0003-3555$\underline{0291}$
}

Copyright (C Published by IJHER Journal, www.ijherjournal.com Rimar Academy, Fatih, Istanbul, 34093 Turkey

All rights reserved 
child, during his development and passing through socio-cultural institutions, integrates these characteristics in the framework of cognitive units that govern his subsequent cognitive functioning.

Key words: Cognitive Integration, Educational Extensions, Intercultural Studies.

\section{التكامل المعرفي في سياق الاراسات البين-ثقافية: \\ الامتدادات التربوية للعلاقة بين إتجاه الكتابة والتمثيل المرات المكاني لمفهوم الزمن نموذجا}

2

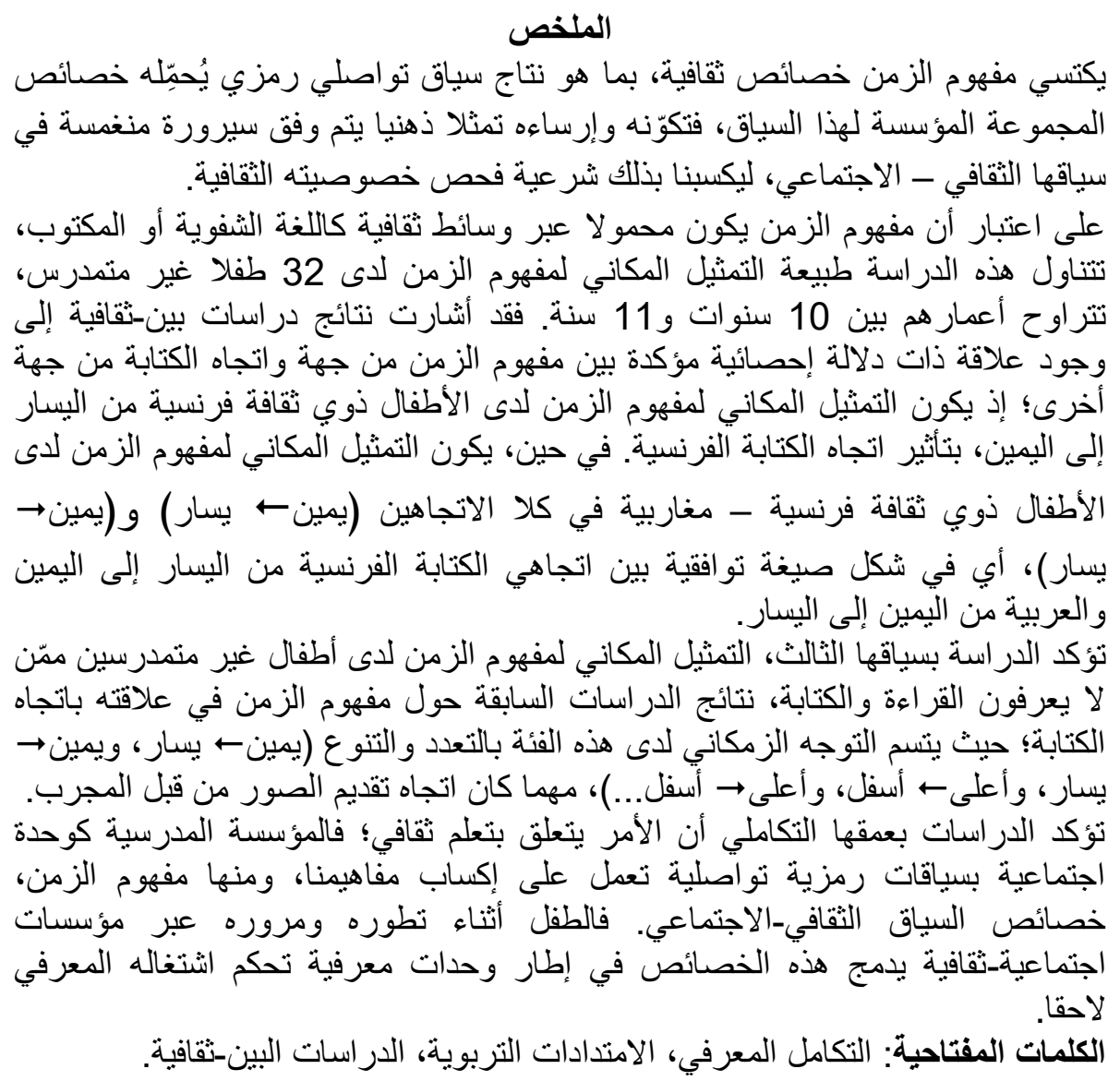

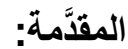

المعرفية والثقافة

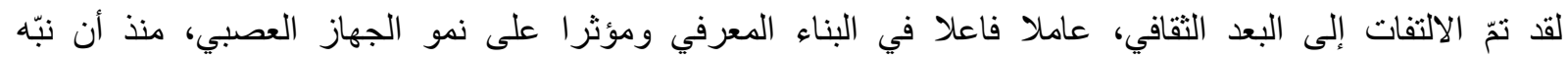
Changeux تضم كل منها آلاف المشابك العصبية، يمكن أن تكون محددة في تفاصيلها من قبل الثنين و عشرين (22) ألف جينة فقط 
(زغبوش، 2011: 46-53). في إثنارة إلى دور العو امل التاريخية والسياق الثقافي والاجتماعي في نمو الفرد وتطوره.

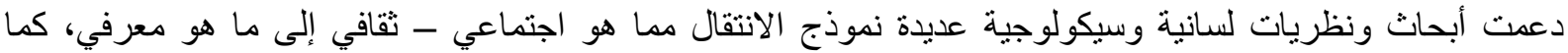
انكبت أخرى حديثة على تحديد خصائص الاشتغال المعرفي بدلالة السئة السياق التقافي ـ الاجتماعي.

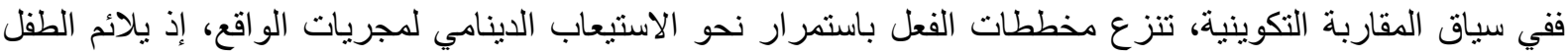

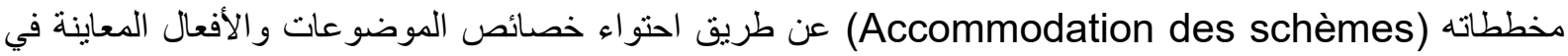

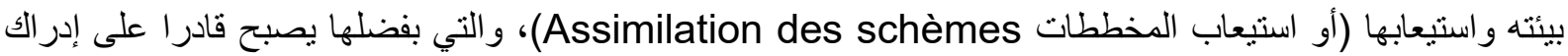

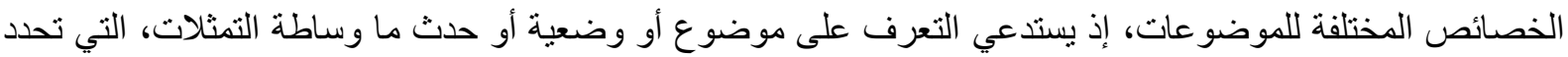

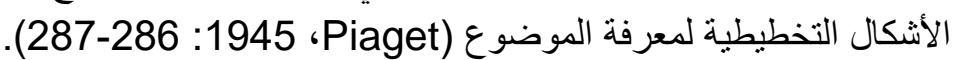

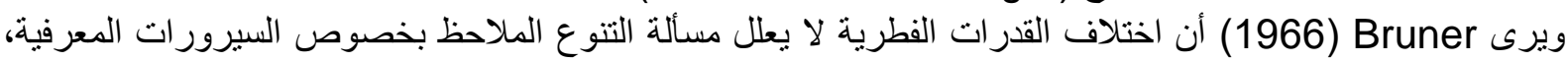

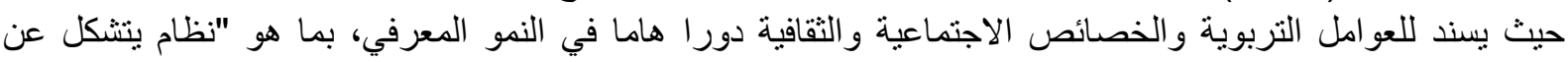

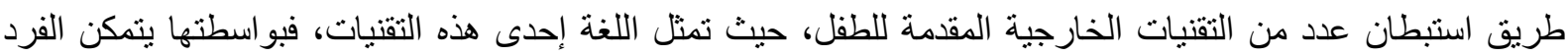

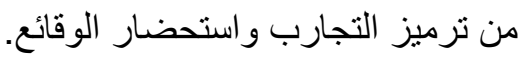

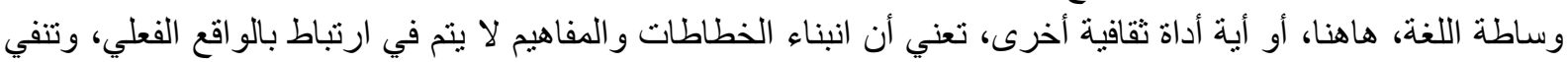

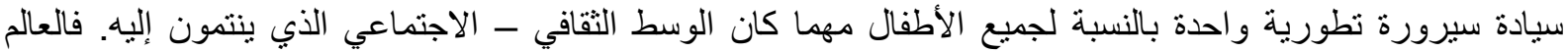

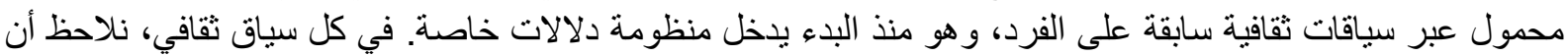

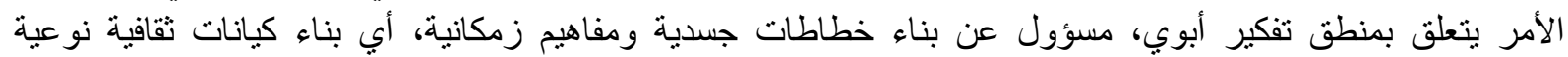
(Benoit)

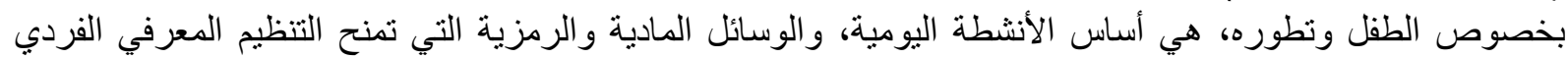

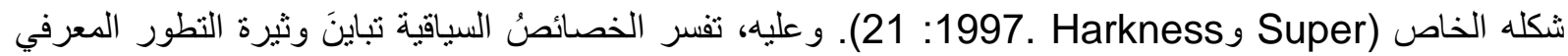
لأطفال من نفس السن ينتمون لثقافات مختلفة، والتنوع اللامحدود في أشكال تنظيمهم لوقائع العالم. توصلت، أيضا، دراسة كل من زغبوش وطرواديك (2012)، على خلفية علاقة ما هو فطري كوني (بنيات الإدر الك،

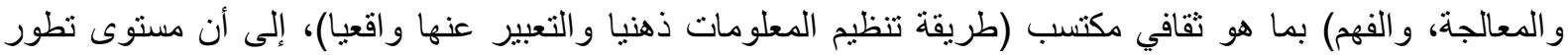

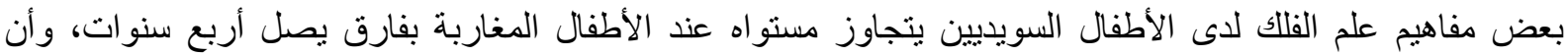

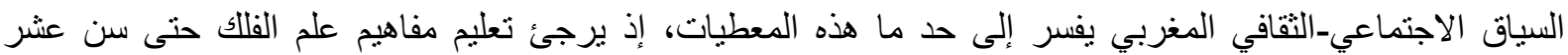

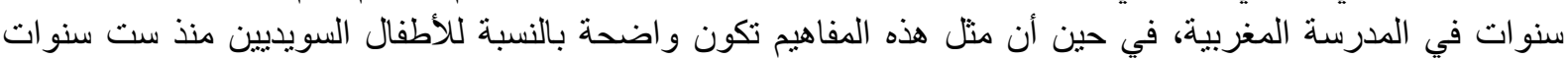

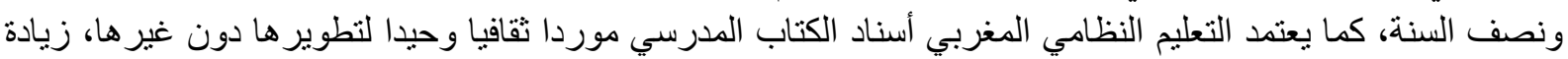

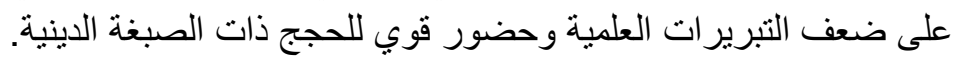

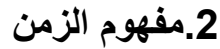

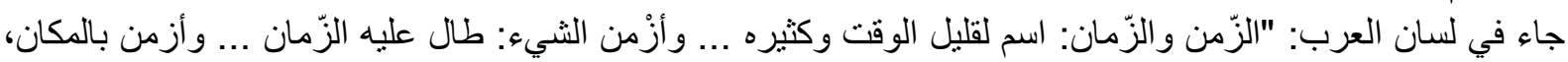

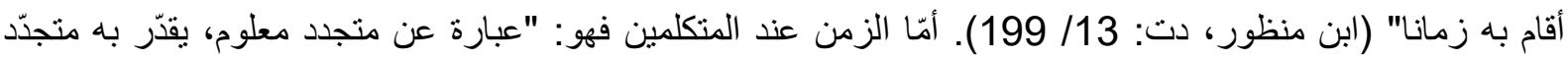

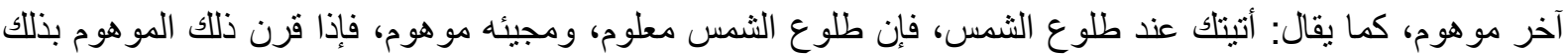

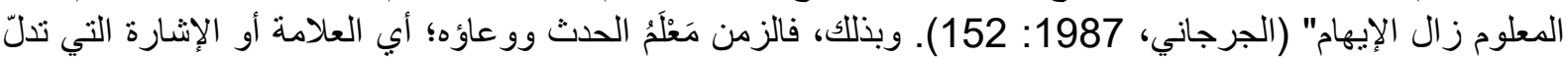

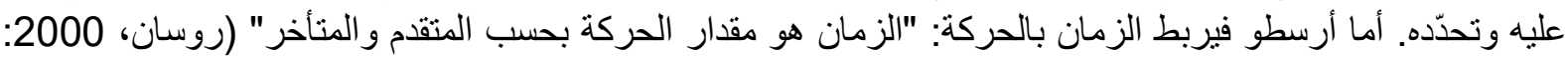

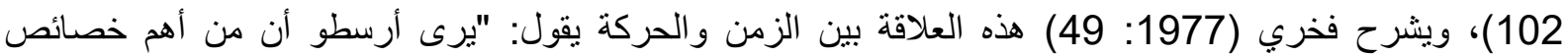

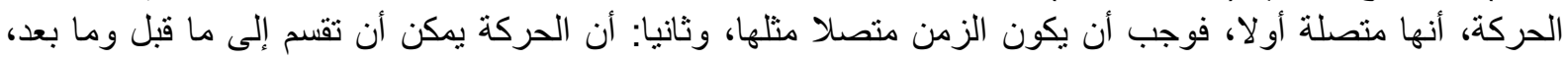

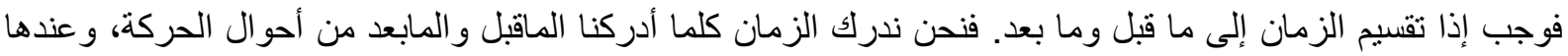

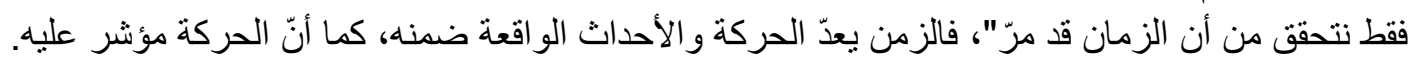

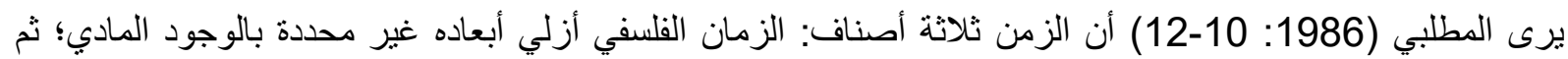

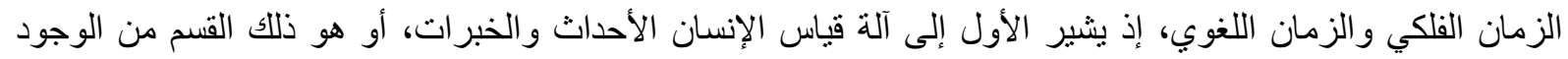


الذي يخضع للزمن ويجري فيه كأحداث الطبيعة و التاريخ، كما أن للثاني أبعادا من قرب وبعد واستمرار و انقطاع، وله

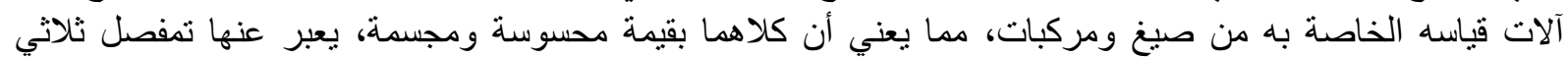
الأبعاد: ماض وحاضر ومستقبل. وعليه، فعلاوة على التضايف بين الأحداث وبعد الزمن، إذ الذية الزمن وعاء وعاء الحركة

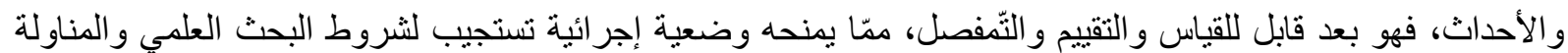
التجريبية. أما الزمن عند العلماء، فهو مفهوم أساس لابد منه لضبط التجربة العلمية، حيث كان من الضروري طرح تصور أسلوب

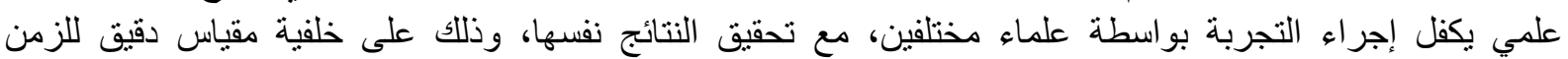

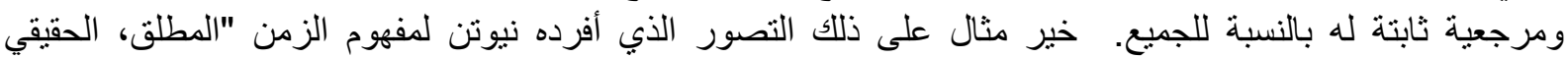

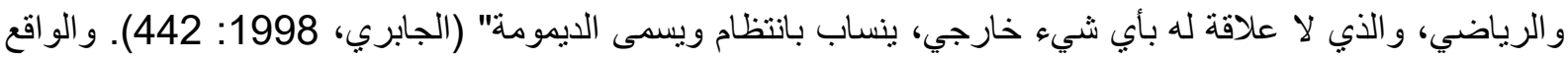

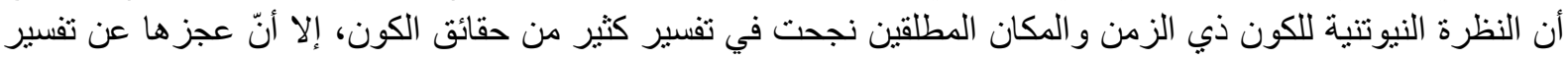

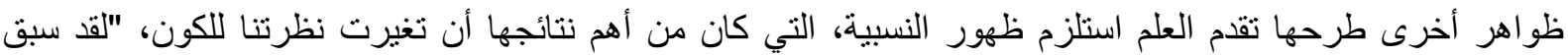

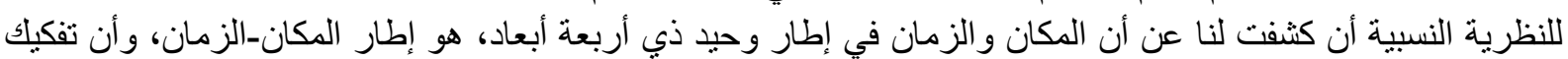

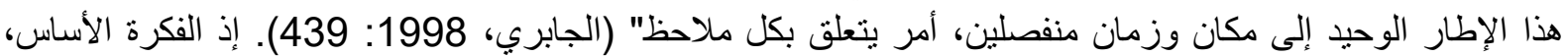

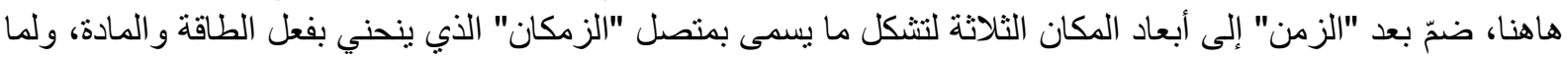

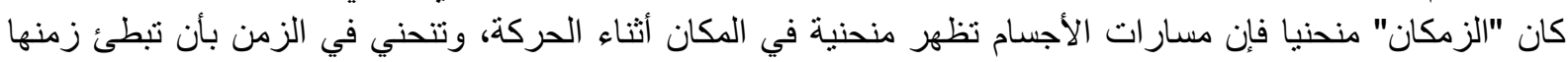

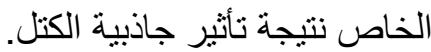
ومنه، تموضع الأحداث نسبة إلى الزمن و المكانية الكان، بتعيين موقعها وتحديد لحظة حدوثها، فهما مساهمان نشيطان في دينامية الكون وليسا خلفية ثابتة لأحداثه.

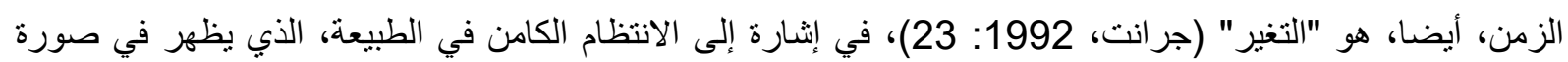

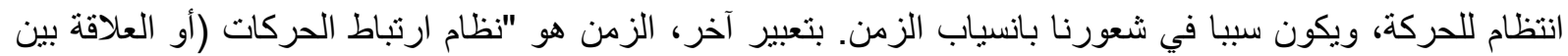

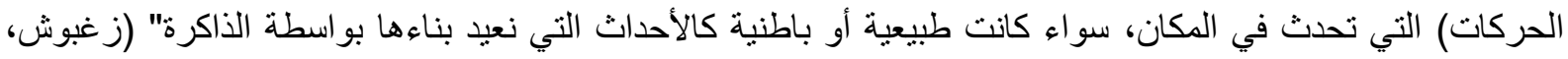

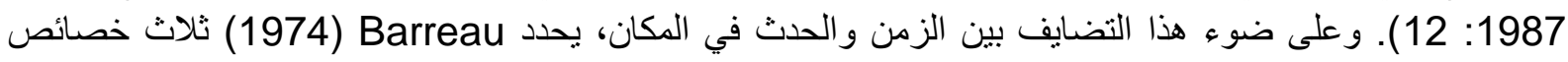

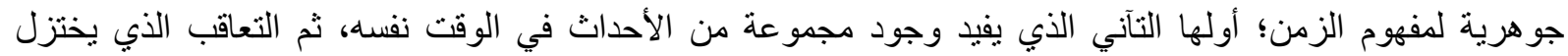

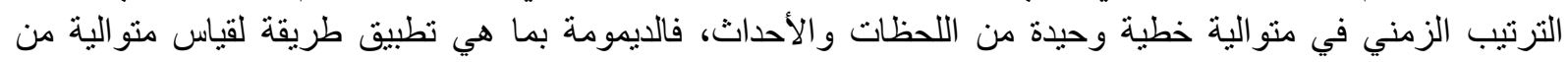

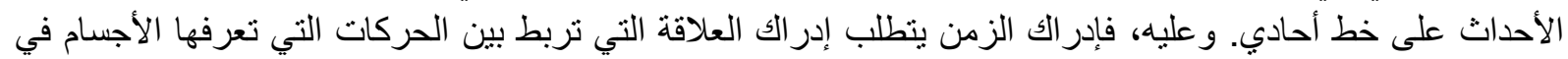

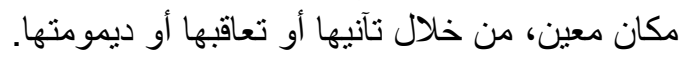

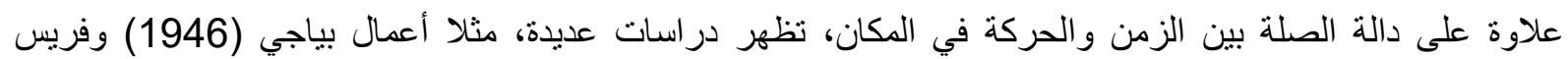

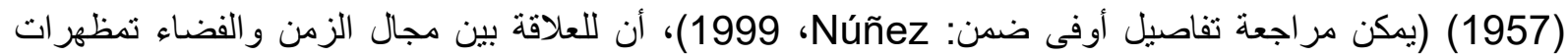

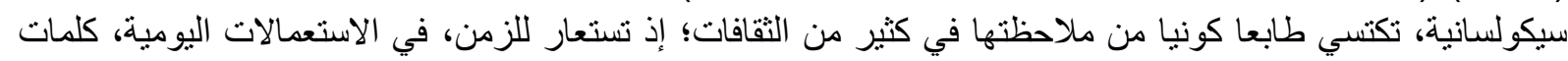

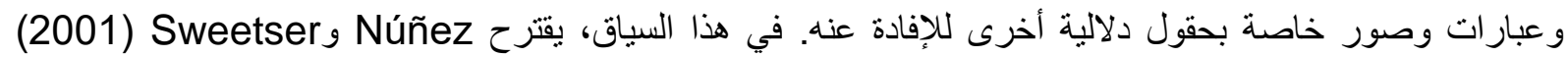

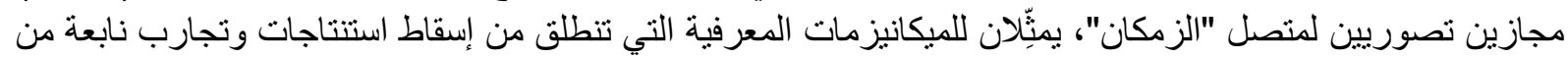

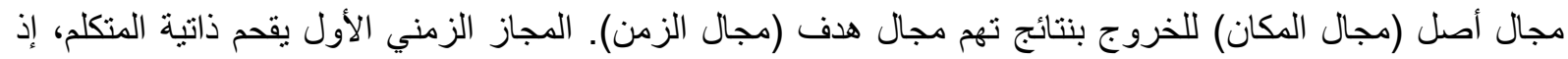

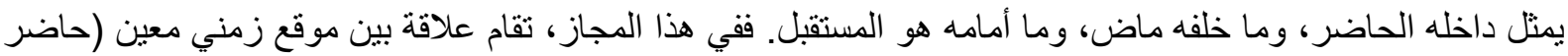

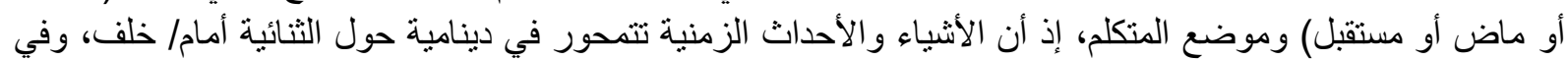

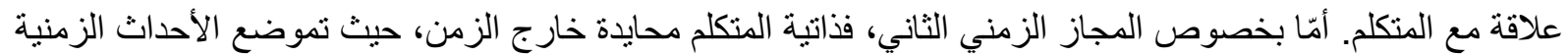

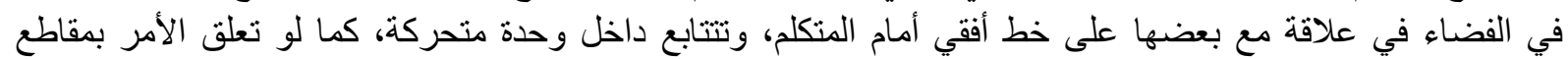
حكاية.

وجدير بالذكر أن المستويات السالفة لمفهوم الزمن (حاضر ، ماض، مستقبل، تزامن، تعاقب، ديمومة) هي مجرد تقاتسيمات

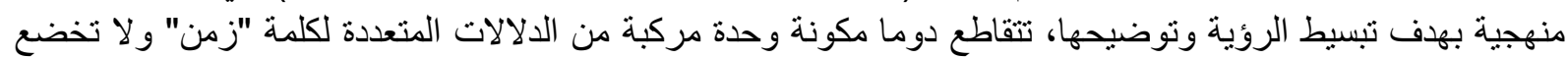

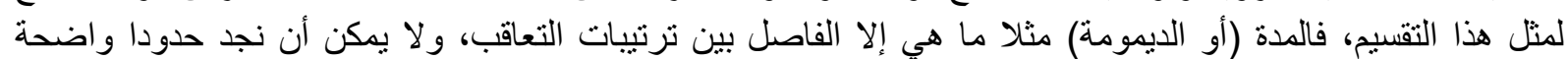

بينهما.

نخلص، ممّا سبق في علاقته بما سننكب على دراسته و التعامل معه تجريبيا، إلى أن مفهوم الزمن هو العلاقة التي تربط

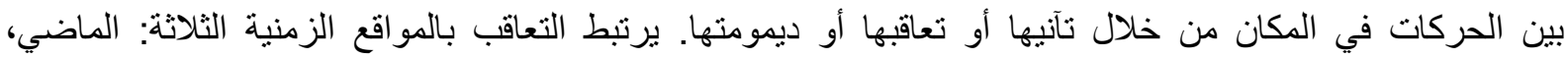




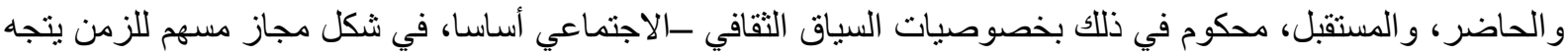
من الماضي إلى المستقبل، مجسدا في التوجه من اليمين إلى اليسار على خط أفقي أو العكس، بتأثثر اتِّاه كتابة اللغة

3.مفهوم الزمن: من السياق الثقافي إلى الاشتغال الذهني

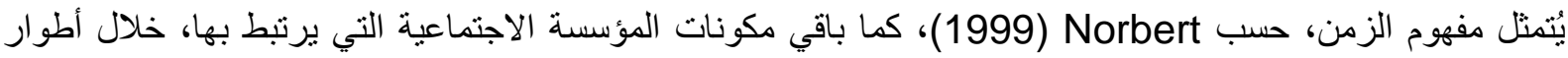

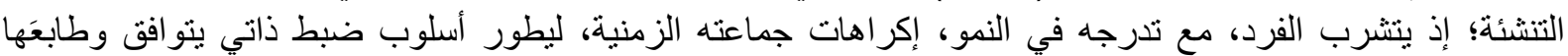
النظامي، هو وعي زمني خاص وجزء أساس من بنية الثخصية. فيبدو ما يقوم به الأفر اد من إدماج لأحداث و القعهم داخل

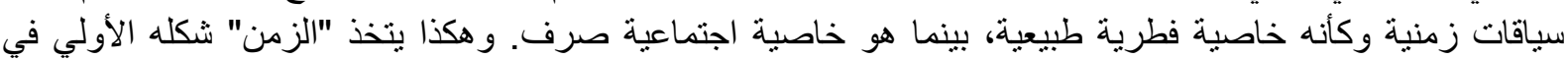

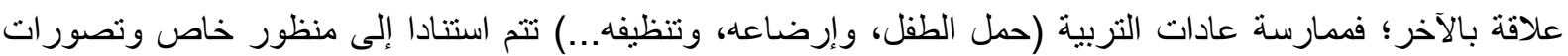

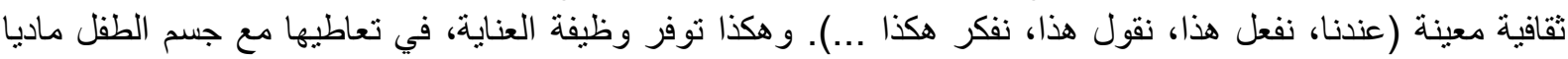

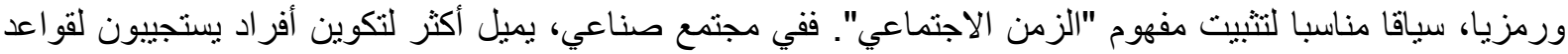

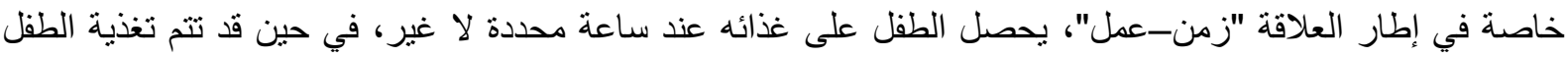

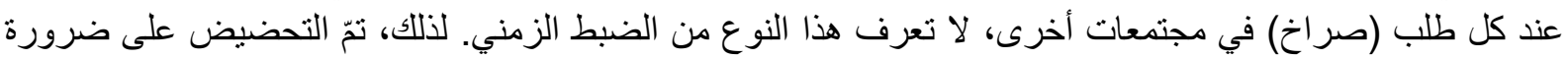
الاهتمام بنمو مفهوم الزمن وتطوره نسبة إلى مجتمع بعينه (Montangero،

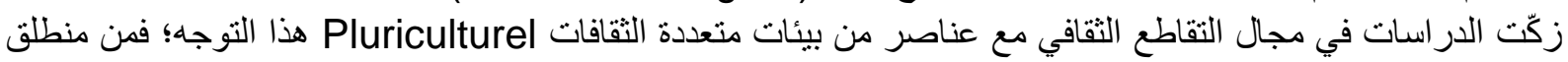
أن المفاهيم تتطور في إطار سياقاتها، ولمعرفة ما إذا كانت مفاهيم ثقافة جديدة تتكون بشكل مندمج مع القيات القوان اعد الاجتماعية

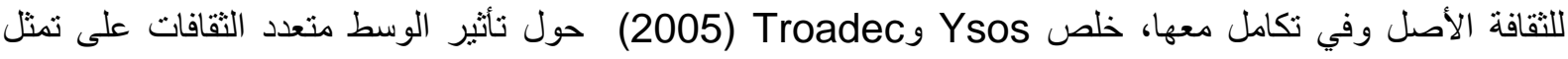

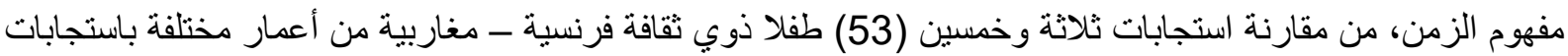

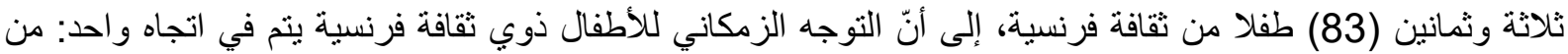

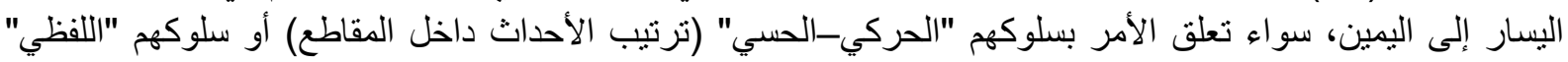

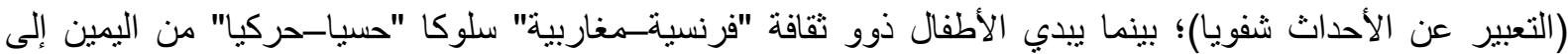

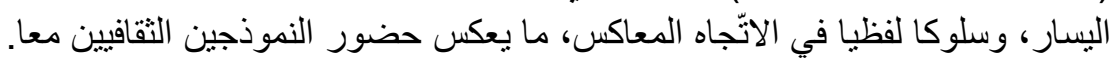

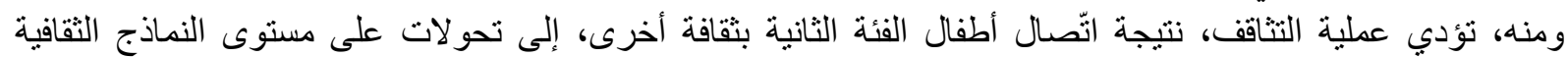

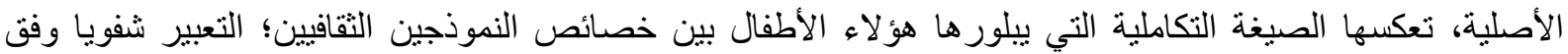

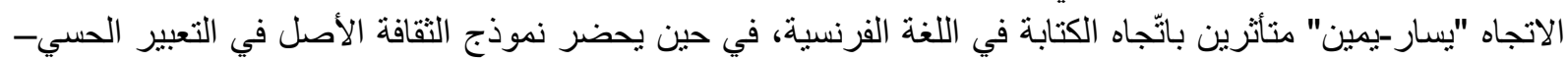

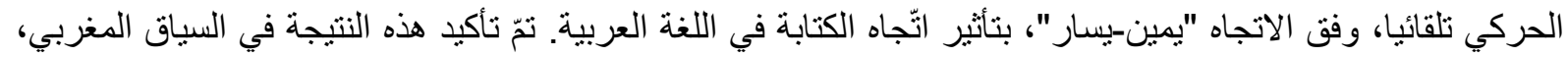

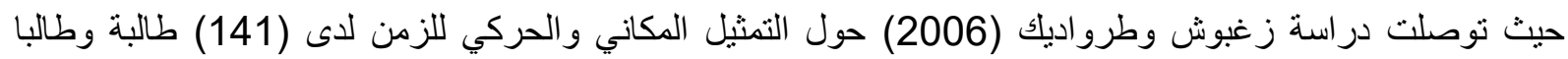

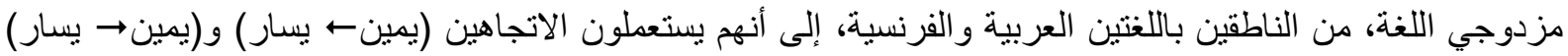

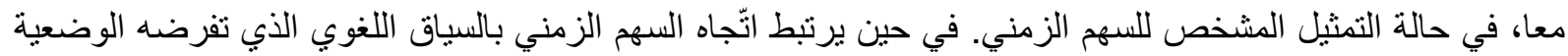

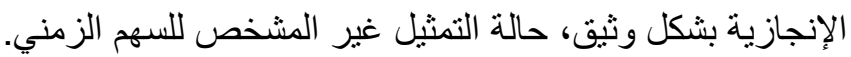

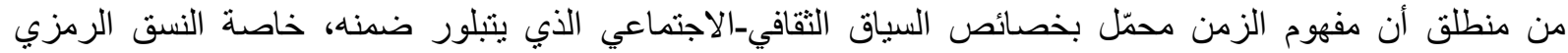

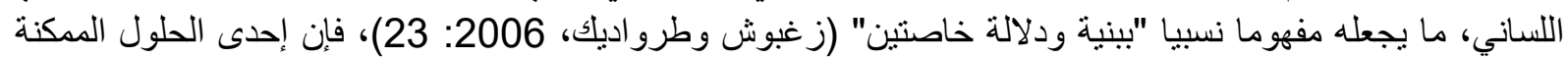

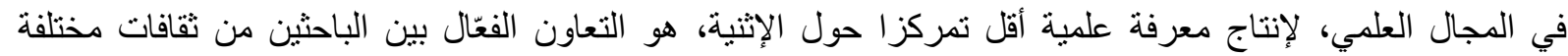

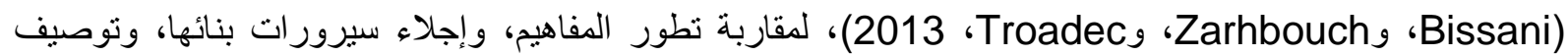

أشكال تمثلها.

4.الدراسة الميدانية: المحددات الثكلية والخطوات المنهجية

1.4.سياق الاراسة وفرضيتها 
مفهوم الزمن هو مفهوم مجرد، تمكن الإحاطة به من طريق الاستعار ات المكانبة؛ إذ يعكس توجّه الحركة في المكان تنو عا

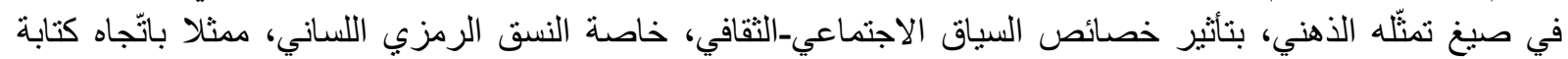
اللغة وقر اءتها. فإذا كان التمثيل المكاني لمفهوم الزمن لدى الأطفال ذوي ثقافة فرنسية من اليسار إلى اليمين، بتأثير اتجاه

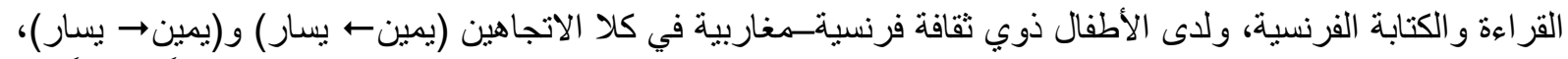

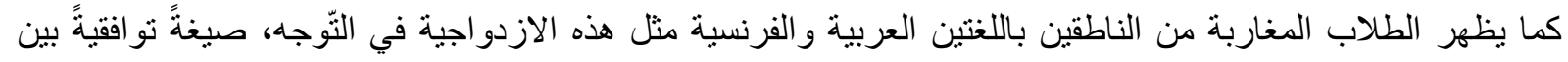

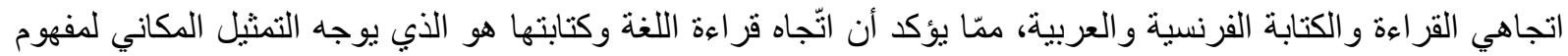

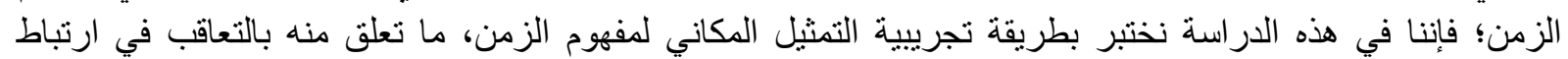

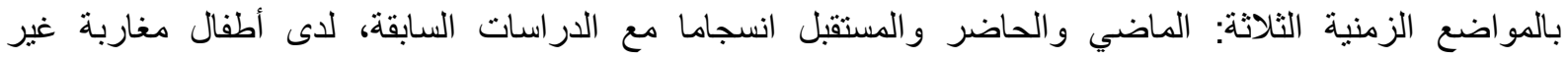

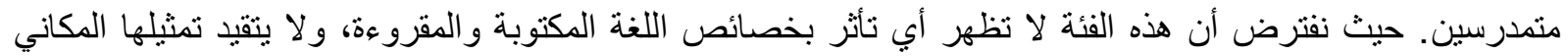

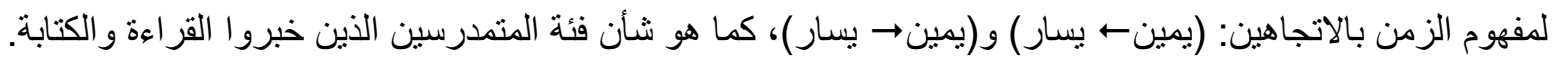

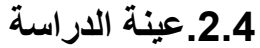

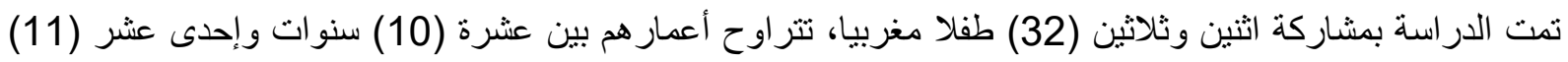
سنة بمتوسط سن بلغ (10,49)، (16) من الذكور و(16) من الإناث، غير منمدرسين، ولا يعرفون القراءة والكتابة، وأغلبهم يزاول حرفة.

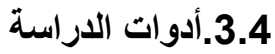

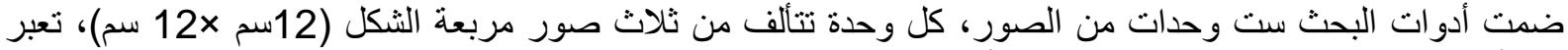

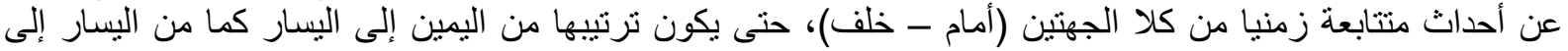
اليمين ممكنا، وذاك حسب معطيات من الجدولين (1) و و(2).

\begin{tabular}{|c|c|c|c|}
\hline الأحداث & الصورة1 & الصورة 2 & الصورة 3 \\
\hline الالوحدة 1 1اظ: & طفل ينام & شخص يو قظه & الطفل ينهض من النوم \\
\hline الوحدة 2: الطبخ & طفلة تقشر الخضر & تطبخها & تقدمها في إناء \\
\hline الوحدة 3: الإفطار & شخص يصب حليبا للطفل & الطفل يشرب الحليب & شرب فيها يغسل الآنية التي \\
\hline الوحدة 4: كرة & طفل يحمل كرة & الطفل يقذف الكرة & الطفل يكسر النافذة بالكرة \\
\hline الوحدة 5: الثاطئ & طفل ذاهب إلى الثاطئ & الطفل يسبح & الطفل يجفف نفسـا \\
\hline الوحدة 6: إنجاز & الطفل ينظر إلى السبورة & الطفل ينجر التمرين & الطفل يصحح التمرين \\
\hline
\end{tabular}

\begin{tabular}{|c|c|c|c|}
\hline الصورة 3 & الصورة 2 & الصورة 1 & \\
\hline الطفل ينهض من نومه & شخص يوقظه & طفل ينام & 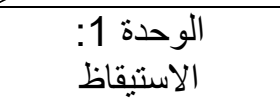 \\
\hline تقدمها في إناء & تطبخها & طفلة تقشر الخطر & الوحدة 2: الطبخ \\
\hline الطفل يغسل الآنية التي شرب & الطفل يشرب الحليب & شخص يصلب حليبا & الوحدة 3: الإفطار \\
\hline الطفل يكسر النافذة بالكرة & الطفل يقذف الكرة & طفل يحمل كرة & الوحدة 4: كرة القدم \\
\hline الطفل يجفف نفسـ & الطفل يسبح & طفل ذاهب إلى الثـاطئ & الوحدة 5: الثاطئ \\
\hline
\end{tabular}




\begin{tabular}{|c|c|c|c|}
\hline الطفل يصحح التمرين & الطفل ينجز التمرين & الطفل بنظر إلى السبورة & الوحدة 6: إنجاز \\
\hline
\end{tabular}

3.4.منهجية الدراسة

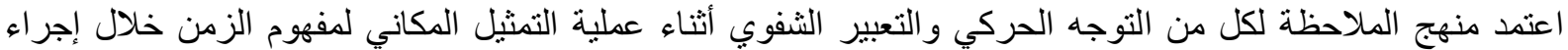

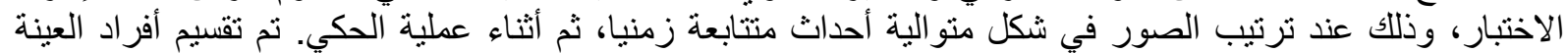

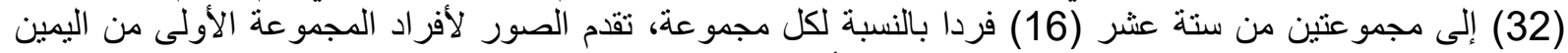

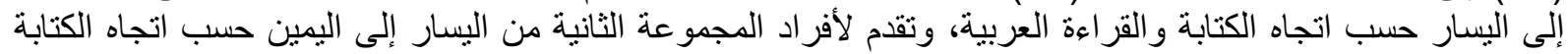

والقر اعة الفرنسية.

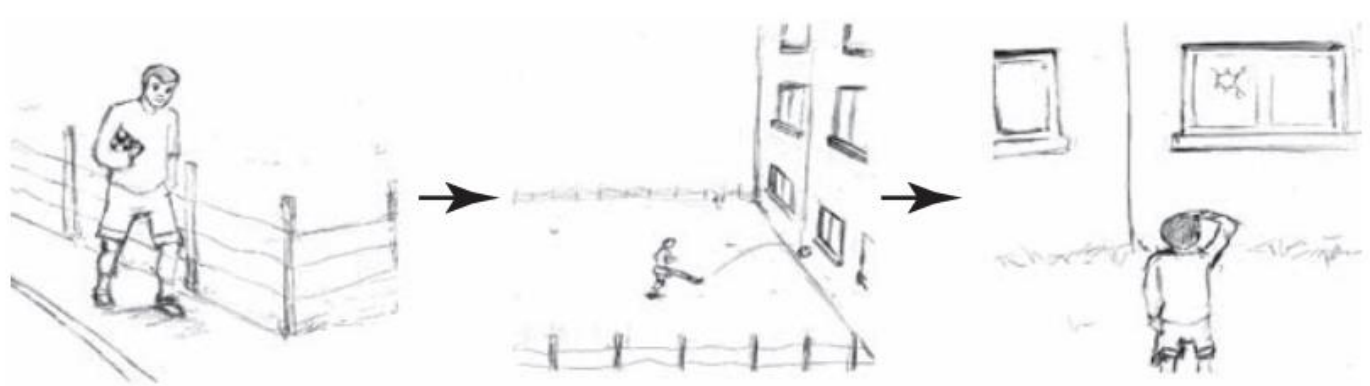

الصورة رقم (1): صور وحدة كرة القدم مرنبة من اليسار إلى اليمين

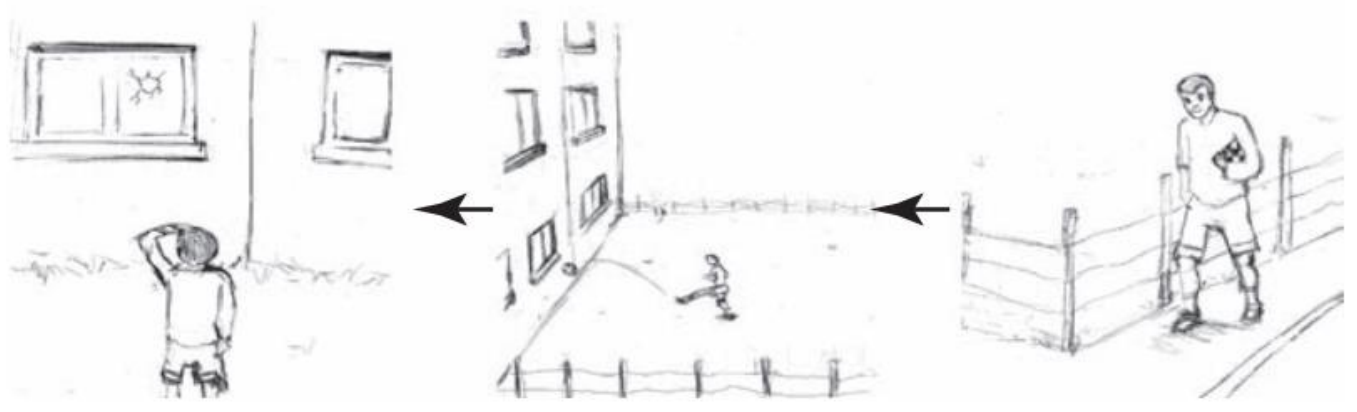

الصورة رقم (2): صور وحدة كرة القدم مرتبة من اليمين إلى اليسار

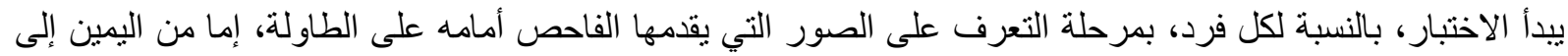

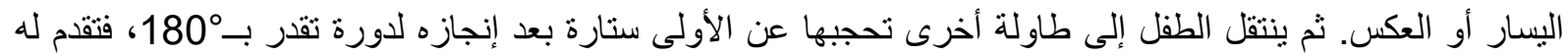

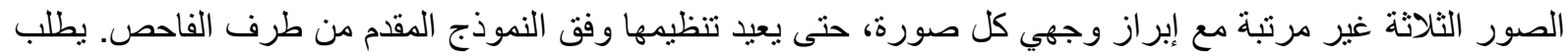

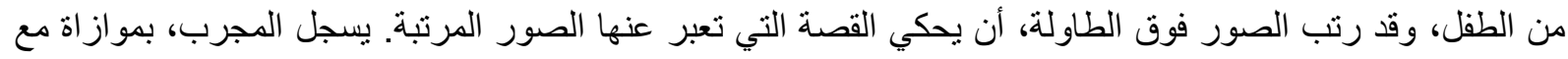

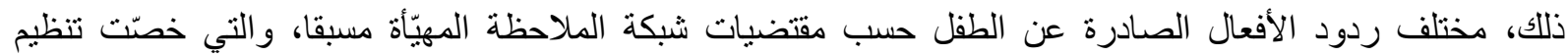

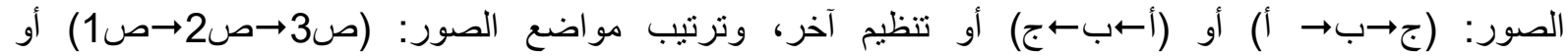

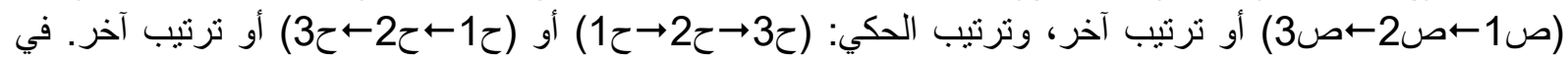

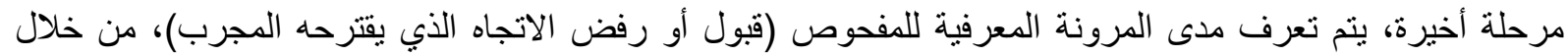

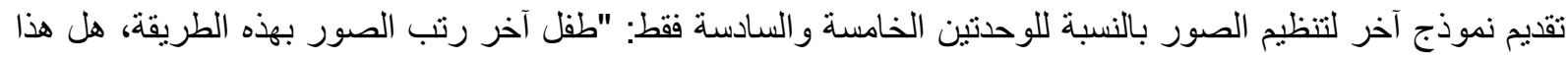

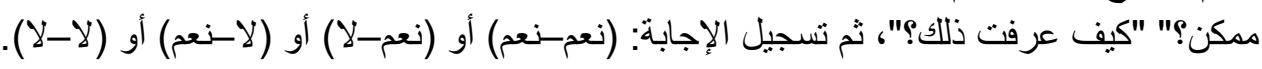

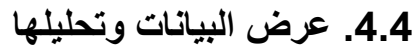




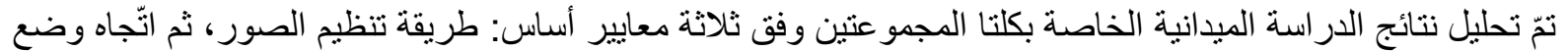

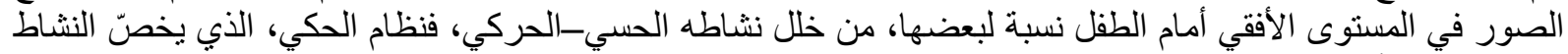

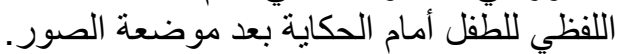

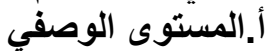
فيما يتعلق بطريقة تنظيم الصوري ، لا يستطيع 2\% فقط من أطفال المرحلة العمرية (11-10) تنظيم الصور وفق الترتيب

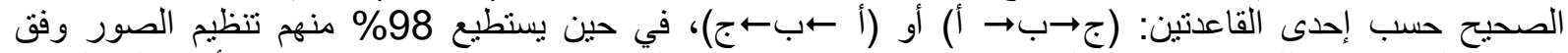

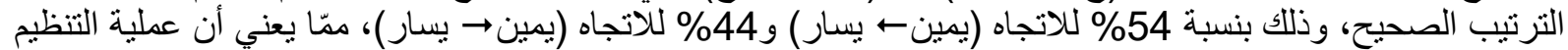
هاته تبقى غير واردة عند فئة عمرية أقل، فعند هذه المرحلة فقط يمكن القول إن إن الطفل يستطيع تكوين مفهوم واضح للزمن، إذ يتمكن من تكوين منو اليات زمنية صحيحة.

\begin{tabular}{|c|c|}
\hline \multicolumn{2}{|c|}{ جدول رقم (3): النسب المئوية لتنظيم الصور } \\
\hline 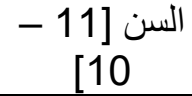 & تجاه تنظيم الصور \\
\hline$\% 44$ & ج ج \\
\hline$\% 54$ & أ \\
\hline$\% 98$ & 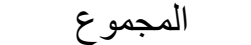 \\
\hline
\end{tabular}

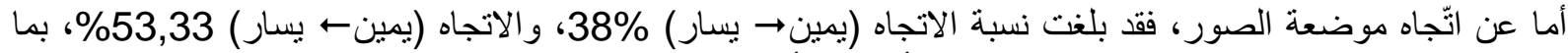

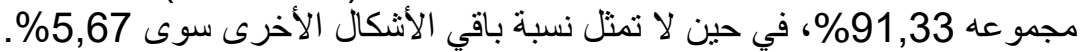

\begin{tabular}{|c|c|}
\hline $\begin{array}{c}\text { السن [10] } \\
\text { 10 }\end{array}$ & اتجاه موضعة الصور \\
\hline$\% 38,00$ & 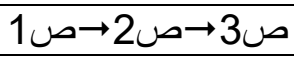 \\
\hline$\% 53,33$ & ص1-صמ2-ص3 \\
\hline$\% 91,33$ & المجموع \\
\hline
\end{tabular}

بخصوص اتجاه الحكي، تقترب النتيجة ممّا نم رصده بخصوص نظام موضعة الصور.

\begin{tabular}{|c|c|}
\hline \multicolumn{2}{|c|}{ كرقم (5): النسب المئوية لاتجاه الحكي } \\
\hline $\begin{array}{c}\text { السن [11 } \\
\text { [11 }\end{array}$ & اتجاه الحكي \\
\hline$\% 44,00$ & $1 \tau \rightarrow 2 \tau \rightarrow 3 \tau$ \\
\hline$\% 54,00$ & $3 \tau \leftarrow 2 \tau \leftarrow 1 \tau$ \\
\hline$\% 98,00$ & المجموع \\
\hline
\end{tabular}

جمعا بين السلوك الحسي-الحركي والسلوك اللفظي، يمثل ما يقرب من 38\% من الأطفال الزمن مكانيا وفق القاعدة

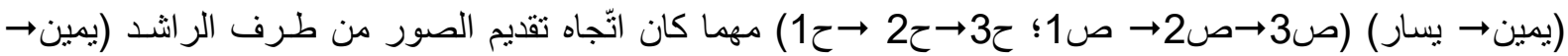

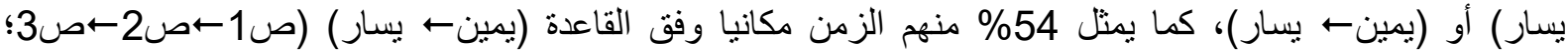

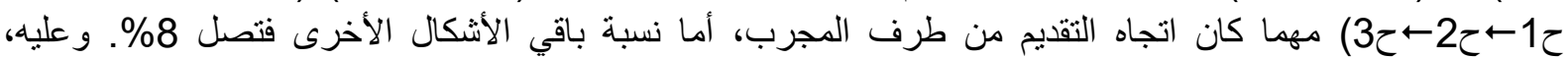
فالتمثيل المكاني لمفهوم الزمن لاعى الطفل غير المتمدرس ثنائي الاتجاه، باعتبار تقارب نسبتي كلا شكلي التمثيل المكاني:

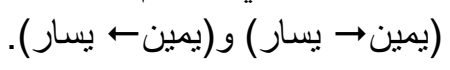




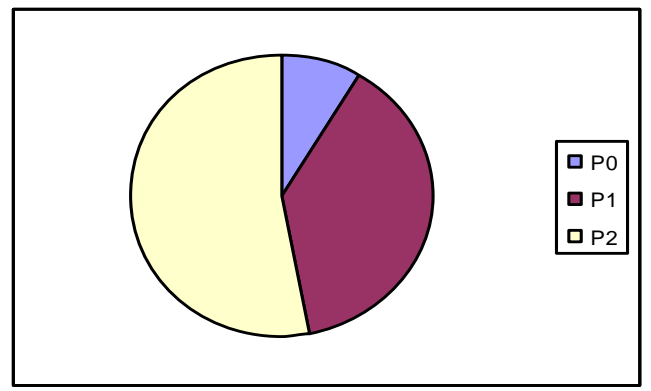

مبيان رقم (2): النسب المئوية للسلوك الحسي-الحركي

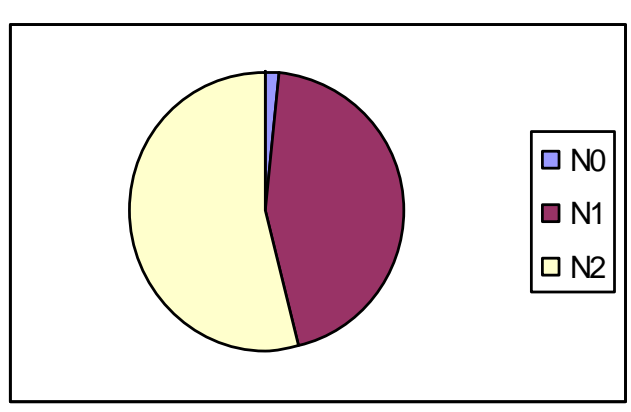

مبيان رقم (1): النسب المئوية للسلوك اللفظي

ب. تأثير اتجاه تقايم الصور

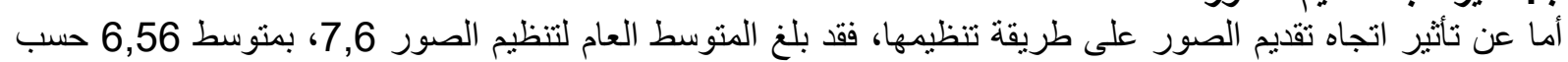

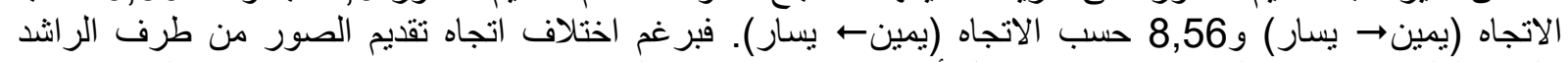

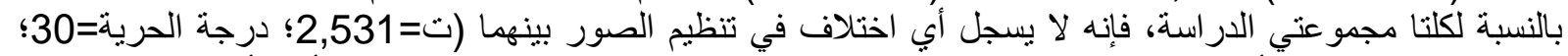

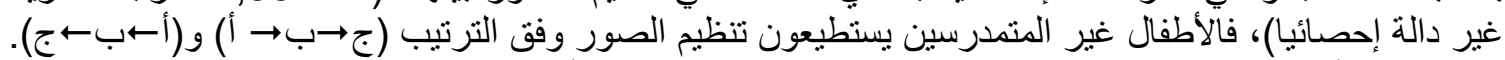

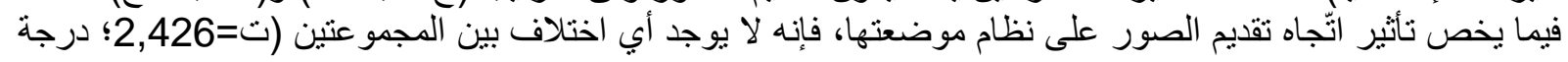

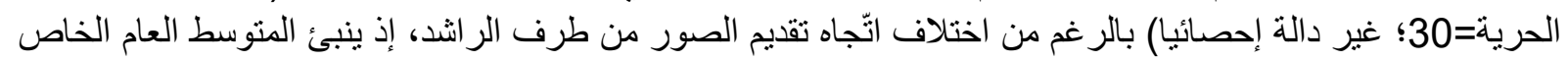

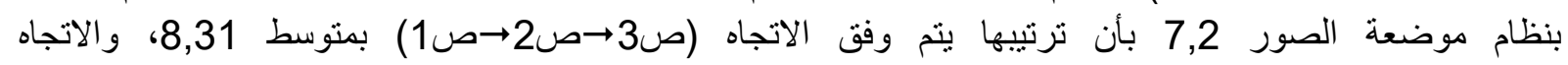

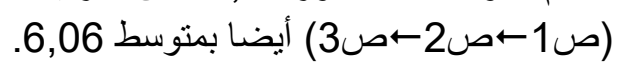

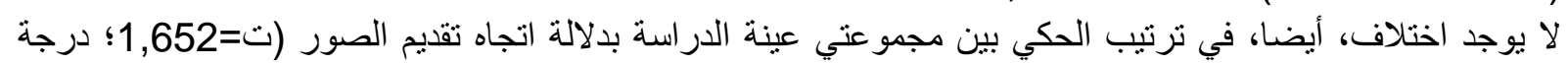

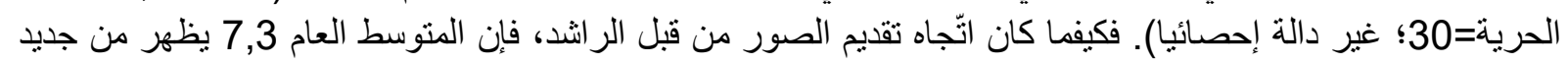

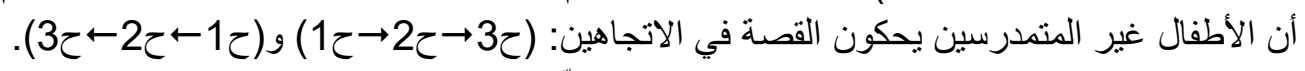

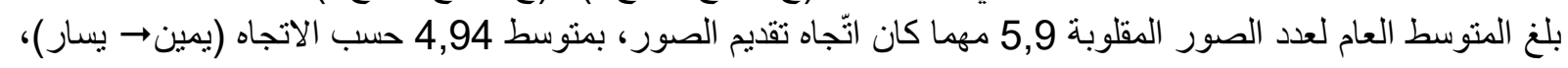

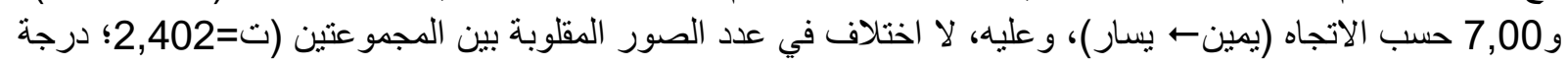
الحرية =30؛ غير دالة إحصائيا).

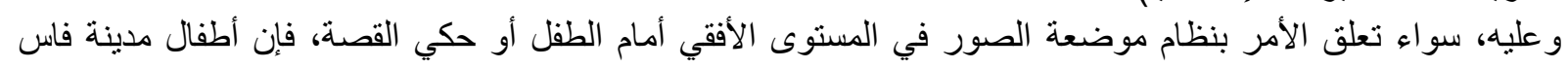

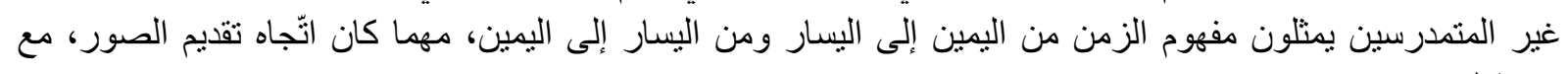

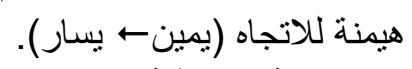
ج.المرونة المعرفية

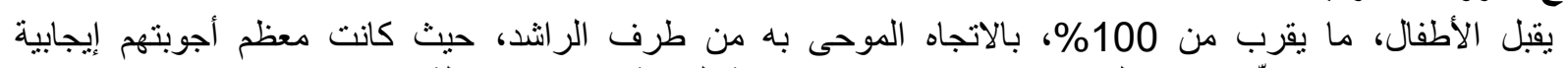

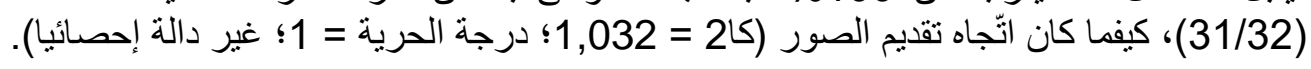

\begin{tabular}{|c|c|c|}
\hline$(V)$ & (نعم) & \\
\hline 1 & 15 & يمين ج يسار \\
\hline 0 & 16 & يمين ـ يسار \\
\hline 1 & 31 & المجموع \\
\hline
\end{tabular}

لكن السؤال المطروح هاهنا؛ هل يتعلق الأمر بقول "نعم" ظنا منهم أنها ما بريد الراشد سماعه أو ينتظره الباحث؟ أو

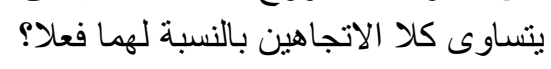




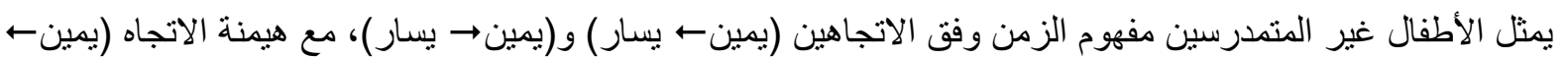

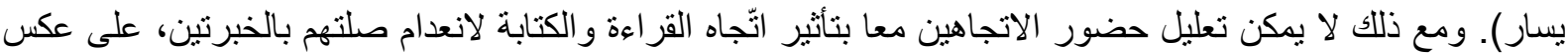

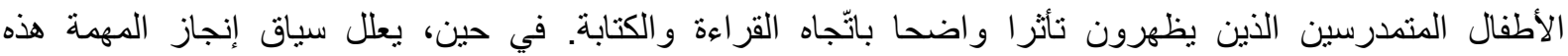

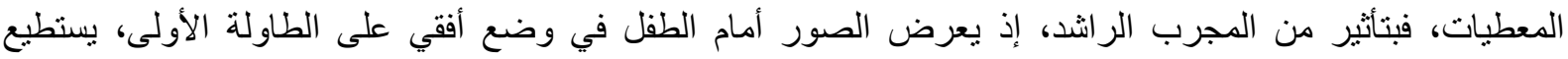

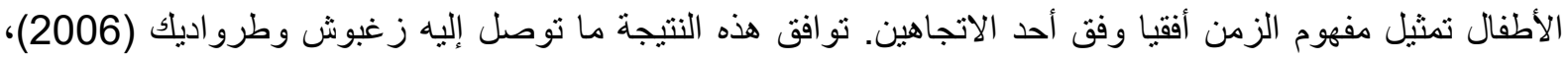

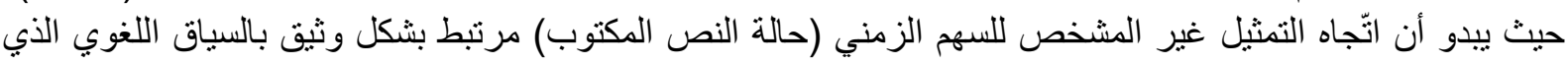

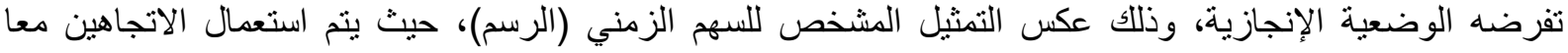

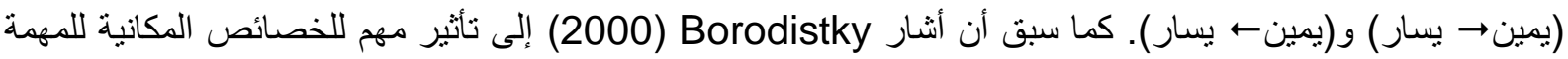
على الإنجاز الزمني للمفحوصنين. علاوة على ذلك، يفضل الأطفال المغاربة غير المتمدرسين الاتجاه (يمينـ يسار)، الذي يحظى في سياق الثقافة العربية

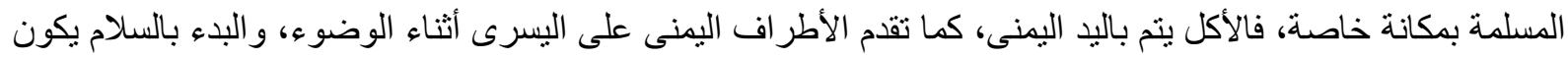

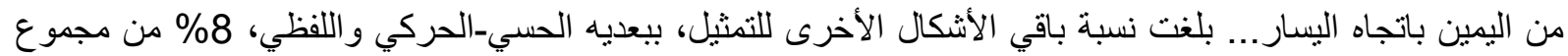

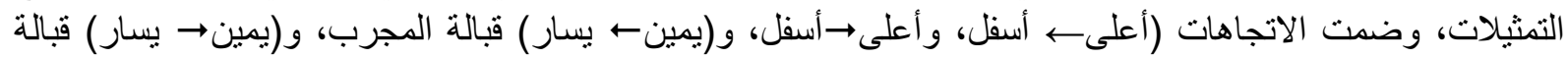
المجري، ووفق خط مائل من اليمين إلى اليسار ، ووفق خط مائل من اليسار إلى اليمين)، حيث كانت معطيات شبكة الإنيا

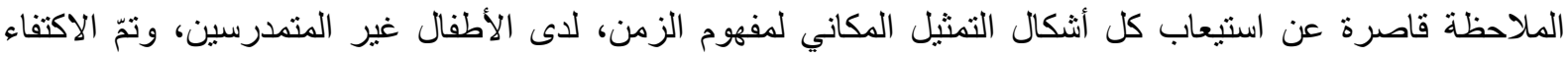

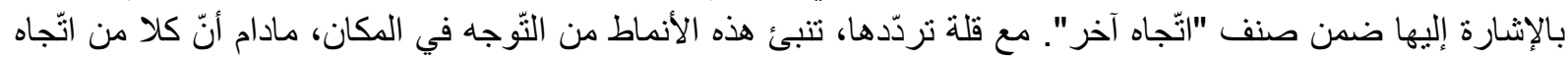

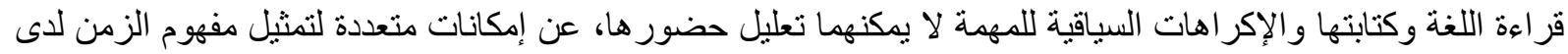

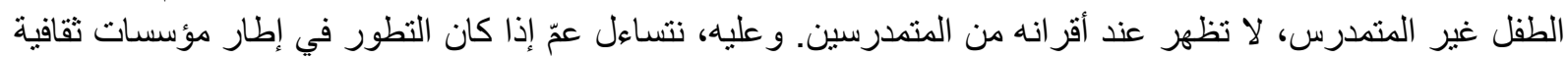

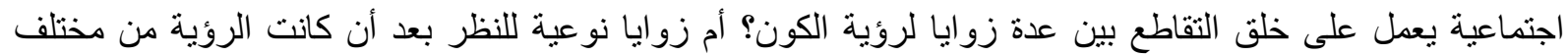

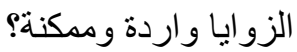

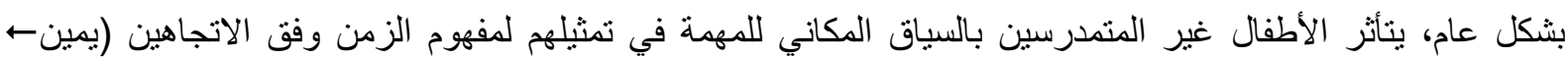

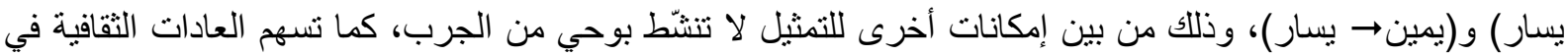

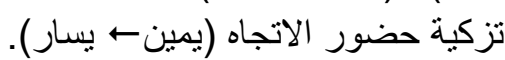
النسق الرمزي اللساني هو حامل ثقافة المجتمع، وعبره يعي أفراد المؤسسة الاجتماعية منظومتهم المعرفية، ويتلقون

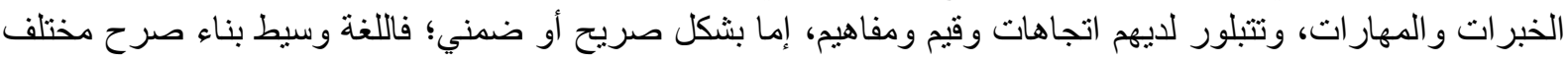

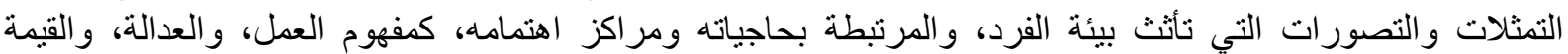

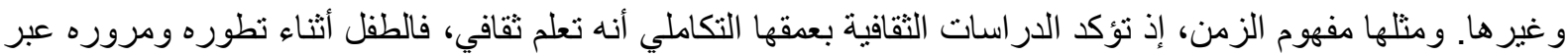

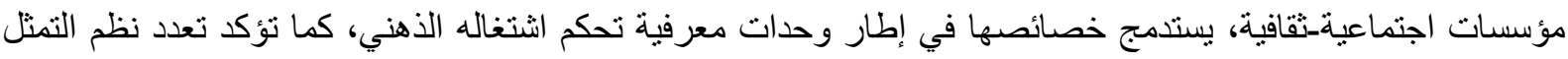
تعكس النماذج النّوليفية لمفهوم الزمن مرونة معرفية وقدرة تكيفية عالية لاى العناصر من أوساط متعددة الثقافات، ينبئ

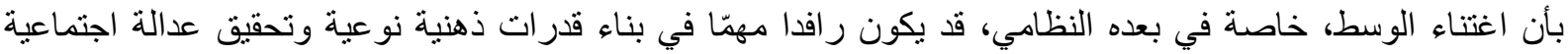

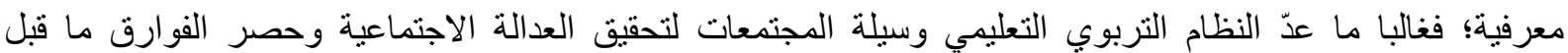

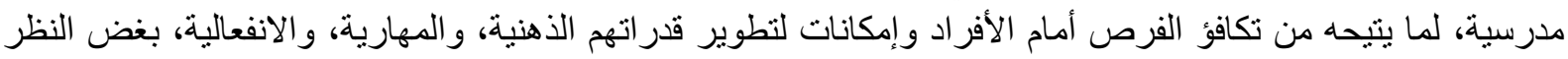

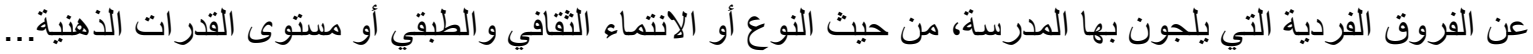

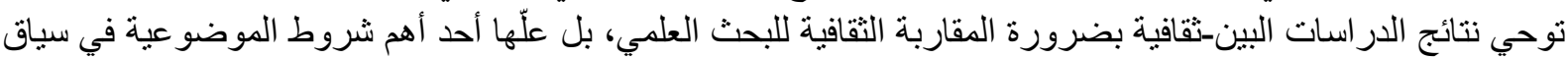

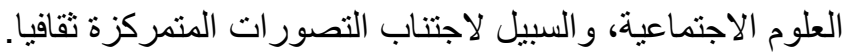

قائمة المصادر والمراجع

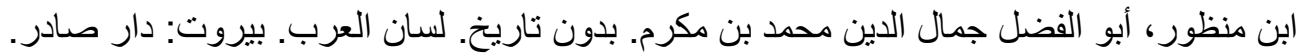

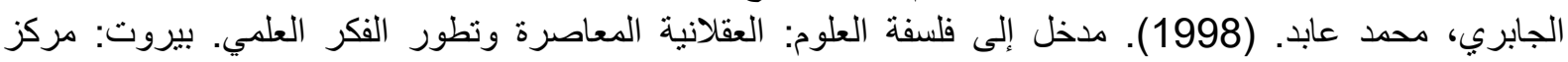
دراسات الوحدة العربية. الطبعة 4. 


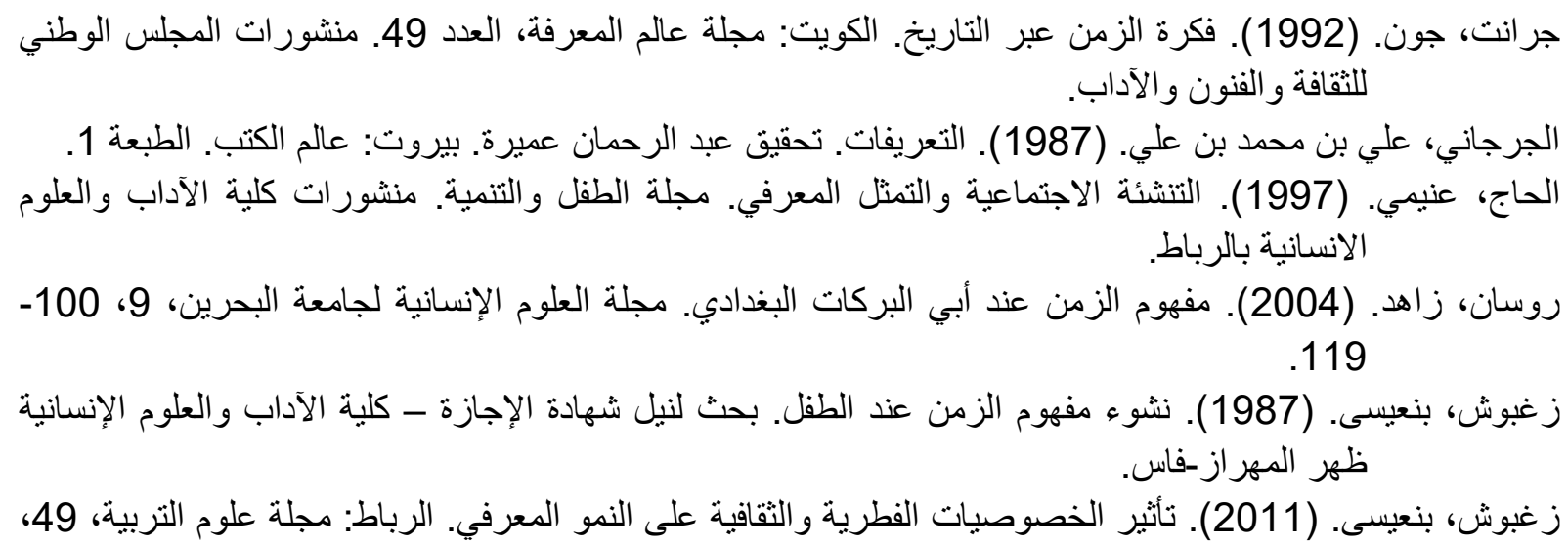
$.53-46$

زغبوش، بنعيسى؛ طرواديك، بيرتر اند. (2006). نأثير اتجاه كتابة اللغة وقراءتها على التمثيل الككاني لمفهوم الزمن.

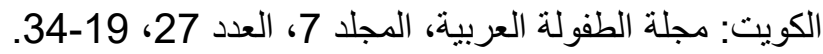

زغبوش، بنعيسى؛ طرواديك، بيرنراند. (2012). العلاقة بين معارف الأطفال العفوية والذاكرات الثقافية الخارجية،

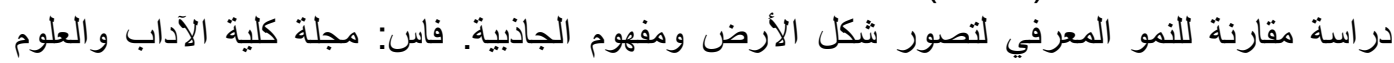
الإنسانية - ظهر المهر از. العدد 19/17،

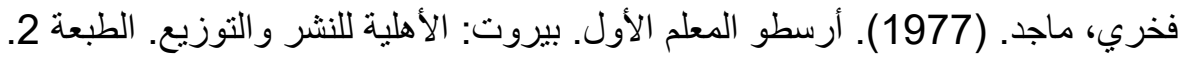

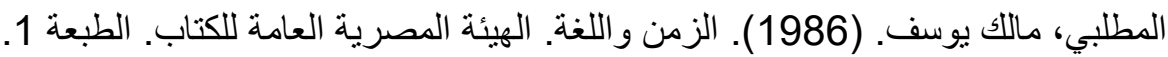

Piaget, J. (1945). La formation du symbole chez l'enfant. Neuchâtel-Paris, Delachaux \& Niestlé.

Barreau, H. (1974). Dictionnaire de philosophie (1840-1852). Paris: Encyclopaedia Universalis et Albin Michel.

Benoit, M. (2002). Mettre aux mondes. Rôle de la culture dans la mise en place du schéma corporel et des notions spatio-temporelles chez l'enfant. Psychologie \& Education, 50, 63-72.

Boroditsky, L. (2000). Metaphoric structuring: Understanding time through spatial metaphors. Cognition, 75, 1-28.

Bruner, J. S. \& Kenney, H. (1966). The development of the concepts of order and proportion in children. In J. S. Bruner. Studies in cognitive growth. New York: Wiley.

Montangero, J. (1977). La notion de durée chez l'enfant de 5 à 9 ans. Paris: PUF. Norbert, E. (1999). Du temps. Paris: Fayard.

Núñez, R. \& Sweetser, E. (2001). Spatial embodiment of temporal metaphors in Aymara: Blending source-domain gesture with speech. Proceedings of the 7th International Cognitive Linguistics Conference. Santa Barbara, University of California, 249-250.

Núñez, R. (1999). Could the Future Taste Purple? Reclaiming Mind, Body and Cognition. Journal of Consciousness Studies, 6, 41-60. 
Super, C. M. \& Harkness, S. (1997). The cultural structuring of child development. In J. Berry, P. Dasen, \& T. Saraswathi (Eds.). Handbook of cross-cultural psychology: Basic processes and human development, 1-39. Needham Heights, MA: Allyn \& Bacon.

Troadec, B.; Zarhbouch, B. \& Bissani, A. (2013). De Toulouse à Fès: une rencontre interculturelle constructive lllustrée par une étude comparative relative à la valeur sociale des langues réalisée auprès d'étudiants en France et au Maroc. Fès : Revue Recherches Cognitives, 2, 11-46.

Ysos, L. \& Troadec, B. (2005). Etude interculturelle du développement de la représentation spatialisée du temps. Psychologie \& Éducation, 3, 27-42. 